\title{
UM NOVO ETHOS EDUCACIONAL NO ENSINO MÉDIO: da formação integral ao empreendedorismo
}

\author{
Marilda de Oliveira Costa ${ }^{1}$ \\ Maria Raquel Caetano2
}

\section{RESUMO}

O presente estudo procurou analisar a emergência do empreendedorismo como um eixo central na formação das juventudes, adotado em reformas educacionais para o ensino médio em dois estados da federação - Mato Grosso e Rio Grande do Sul, orientadas pela Base Nacional Comum Curricular (BNCC) e Novo Ensino Médio. Tais reformas alteram as possibilidades de educação integral e omnilateral no Ensino Médio e como educação básica. As recentes legislações relativas a políticas de empreendedorismo estaduais alteram projeto de educação pública ao acenarem para um novo ethos educacional voltado para atender a lógica do desemprego, da precarização, da robotização e uberização do trabalho na era do capital improdutivo. No desenvolvimento metodológico utilizamos a pesquisa bibliográfica e a análise documental.

Palavras-chave: Formação Integral. Ensino Médio. Empreendedorismo.

\section{A NEW EDUCATIONAL ETHOS IN HIGH SCHOOL: FROM COMPREHENSIVE TRAINING TO ENTREPRENEURSHIP}

\begin{abstract}
This study sought to analyze the emergence of entrepreneurship as a central axis in the formation of youth, adopted in educational reforms for secondary education in two states of The federation - Mato Grosso and Rio Grande do Sul, guided by the Common National Curriculum Base (BNCC) and New High School. Such reforms alter

\footnotetext{
1 Pós Doutoramento em Ciências da Educação, na especialidade Organização Escolar na Universidade do Minho-Portugal (UMINHO). Docente na Universidade do Estado de Mato Grosso (UNEMAT). Atua no Programa de Pós Graduação em Educação (PPGEdu/UNEMAT). Integra o Grupo de Pesquisa Juventude, Cultura e Políticas Públicas e da rede de Estudos e Pesquisas em Planejamento e Gestão Educacional - REPLAG; Rede Latino-Americana e Africana de Pesquisadores em Privatização da Educação (RElaappe). Orcid iD: https://orcid.org/0000-0001-6859-0041.E-mail: marilda.costa@unemat.br

2 Doutora em Educação pela Universidade Federal do Rio Grande do Sul (UFRGS). Docente no Instituto Federal de Educação, Ciência e Tecnologia Sul-riograndense (IFSul)-Brasil. Atua no Programa de pós-graduação em Educação Profissional e Tecnológica -Mestrado em Rede-ProfEPT. Integra o Grupo de Pesquisa Relações Público e Privado na Educação (GPRPPE)/ UFRGS e é líder do Grupo de Estudos e Pesquisas em Educação Profissional e Tecnológica (GEPEPT)/IFSUl. Orcidld: http://orcid.org/0000-0001-6973-908X. E-mail: caetanoraquel2013@gmail.com
} 
the possibilities of integral and omnilateral education in high school and as basic education. Recent legislation on state entrepreneurship policies alters the public education project by pointing to a new educational ethos aimed at meeting the logic of unemployment, precariousness, robotization and uberization of work in the era of unproductive capital. In the methodological development we used bibliographical research and documental analysis.

Keywords: Integral Training. High school. Entrepreneurship.

\section{UN NUEVO ETHOS EDUCATIVO EN LA ESCUELA SECUNDARIA: DE LA FORMACIÓN INTEGRAL AL EMPRENDIMIENTO}

\section{RESUMEN}

El presente estudio buscó analizar el surgimiento del emprendimiento como eje central en la formación de la juventud, adoptado en las reformas educativas para la educación secundaria en dos estados de la federación - Mato Grosso y Rio Grande do Sul, guiados por la Base Curricular Nacional Común (BNCC) y New High School. Tales reformas alteran las posibilidades de la educación integral y omnilateral en el Bachillerato y como Educación Básica. La reciente legislación sobre políticas estatales de emprendimiento altera el proyecto de educación pública al señalar un nuevo ethos educativo orientado a responder a la lógica del desempleo, la precariedad, la robotización y uberización del trabajo en la era del capital improductivo. En el desarrollo metodológico se utilizó la investigación bibliográfica y el análisis documental.

Palabras clave: Formación integral. Escuela secundaria. Emprendimiento.

\section{INTRODUÇÃO}

O artigo tem por objetivo problematizar a relação entre educação integral e o empreendedorismo que ganha fôlego e protagonismo nas reformas educacionais de estados como Mato Grosso e Rio Grande do Sul, em atenção às reformas do Novo Ensino Médio e a Base Nacional Comum Curricular (BNCC). Tais reformas, como politica educacional, vêm se afastando dos princípios politico-pedagógicos de uma educação integral e omnilateral voltada para a formação das juventudes. Ao mesmo tempo, emerge um novo ethos educacional no contexto de profundas mudanças no mundo do trabalho e da produção no capitalismo neoliberal.

A relação entre o Ensino Médio e formação integral proposta pelos educadores, não dialoga com os interesses empresariais, que têm entrado na esfera escolar através do empreendedorismo e exigem que os indivíduos estejam em constante formação para atenderem às demandas do 
mercado. Aprender a empreender se constitui um dos pilares da educação para o século 21, em que a formação integral e omnilateral dos estudantes acaba se distanciando através de propostas educacionais que cerceiam o direito a essa educação ao disputar o conteúdo educacional, especialmente a partir da reforma do ensino médio de 2017.

No contexto mais amplo de reestruturação produtiva, o aumento do contingente de trabalhadores desempregados cria uma reserva e induz a concorrência. O acesso ao emprego torna-se cada vez mais escasso e, com isso, o capital dissemina seus meios ideológicos de combatê-lo, e o empreendedorismo se constitui numa dessas formas. Convém lembrar que o empreendedorismo vem ocupando cada vez mais espaço nos currículos da educação pública brasileira e, atualmente, é um dos eixos do Novo Ensino Médio.

No desenvolvimento metodológico, utilizamos o levantamento e a análise de documentos oficiais e institucionais, relatórios, e aportes teóricos, como: Puello-Socarrás (2008; 2010); Abdala e Puello-Socarrás (2019), Frigotto; Ciavatta; Ramos, (2012) entre outros. Procedemos à análise de documentos e mapeamento de programas de empreendedorismo, buscando relacionar com o tema em estudo.

\section{O Ensino Médio e a formação integral}

O Ensino Médio, última etapa da educação básica, reflete o dualismo na educação brasileira "[...] pelo fato de ser nesse nível de ensino que se revela com mais evidência a contradição entre o capital e o trabalho, [...] pois afinal [...] destina-se à formação propedêutica ou à preparação para o trabalho?" (FRIGOTTO; CIAVATTA; RAMOS, 2012, p. 31).

O caráter dual de educação, presente ao longo da história, "expressou-se por meio da oferta de escolas que se diferenciavam segundo a classe social que se propunham a formar: trabalhadores ou burgueses" (KUENZER, 2007, p. 1155-1156). Marcado por uma perspectiva reducionista de ensino, reservou aos estudantes da classe trabalhadora, o desenvolvimento de habilidades cognitivas instrumentais, caracterizando uma formação que 
atende aos interesses da burguesia, alinhando o papel da educação aos preceitos da reprodução incontrolável do capital.

Nós acreditamos em uma formação humana integral e omnilateral, entendida como desenvolvimento total do ser humano em todas as dimensões, ou seja, da sua integralidade física, mental, cultural, política e científico-tecnológica. Nessa experiência formativa, serão reveladas as potencialidades que cada sujeito possui (RAMOS, 2007). Krueger (2019), citando Ramos, reforça a importância de que, na Educação Básica e no Ensino Médio, particularmente, sejam dadas oportunidades formativas para que os estudantes possam desenvolver as potencialidades, permitindo-Ihes que essas possam ser desveladas e reveladas, a fim de que possibilitem a esses sujeitos estruturar suas escolhas (RAMOS, 2014).

Ciavatta defende que a educação deve ser, obrigatoriamente, emancipatória. Segundo ela, "um currículo crítico emancipatório deve proporcionar aos jovens estudantes uma leitura ampliada do mundo e uma preparação intelectual e profissional para atuar e obter meios de vida [...]" (CIAVATTA, 2008, p. 54), como forma de lutar pelos seus direitos e resistir às políticas de exclusão. Diante disso, traz-se a importância da concepção do currículo integrado que pressupõe a educação geral como indissociável da educação profissional, na perspectiva da formação integral e integrada, na qual os conhecimentos teóricos e práticos sejam indissociáveis. Assim, existe a possibilidade de superação do caráter dual da educação, que tem acompanhado a constituição do Ensino Médio ao longo da história.

$\mathrm{Na}$ contramão dessa discussão, temos o processo de Reforma do Ensino Médio, cuja proposta, apresentada inicialmente por meio da Medida Provisória n 746/2016 e, posteriormente, aprovada através da Lei $n^{\circ}$ 13.415/2017, não apresenta mudanças apenas na sua organização, mas também nas formas de oferta e no financiamento. Seu conteúdo traz alterações na Lei de Diretrizes e Bases da Educação no que se refere à organização curricular e pedagógica. $O$ artigo 36 da LDB passa a ter nova redação, estabelecendo que "o currículo do ensino médio será composto pela Base Nacional Comum Curricular e por itinerários formativos" (BRASIL, 
2016, p. 1), a serem definidos pelos sistemas de ensino, com ênfase nas seguintes áreas de conhecimento ou de atuação profissional: linguagens e suas tecnologias; matemática e suas tecnologias; ciências da natureza e suas tecnologias; ciências humanas e sociais aplicadas; formação técnica e profissional.

Assim, o currículo passará a ter uma primeira parte comum a todos os estudantes, tendo como foco de estudo a Base Nacional Comum Curricular (BNCC), com 1.800 horas, e a segunda parte, com cinco itinerários formativos, com 1.200 horas, totalizando 3.000 horas no ensino médio. Há de se destacar que nessas três mil horas podem ser incorporadas e aproveitadas cargas horárias de outros cursos.

A Reforma do Ensino Médio e a BNCC têm sido a justificativa usada para a introdução do empreendedorismo como conteúdo da educação, o que também tem sido apresentado por diferentes instituições privadas como conteúdo da BNCC. A Reforma do Ensino Médio aprovada em consonância com a BNCC, convertida na Lei $N^{0} 13.415$, de 16 de fevereiro de 2017, que alterou a Lei de Diretrizes e Bases da Educação apresenta características de uma grande aliança entre instituições privadas com o apoio da grande mídia e dos partidos políticos que sustentaram o impeachment da presidente Dilma Rousseff, denominado Movimento pela Base ${ }^{3}$.

O Ensino Médio, que visa à formação dos jovens brasileiros, passou a ser alvo dos interesses do capital, representado pelo setor privado para qualificar as novas formas de organização do trabalho produtivo, além de influenciar o conteúdo que será abordado nas escolas públicas, esvaziado através de seus métodos, ou seja, novas formas de gestão e padronização do currículo convertendo a gestão da educação, da escola e da sala de aula em uma gestão gerencial focada para resultados, cujo foco são as

\footnotetext{
${ }^{3}$ O Movimento pela Base se apresentou como um grupo não governamental de profissionais e pesquisadores da educação que atua, desde 2013, para facilitar a construção de uma base de qualidade. Esse movimento foi coordenado pela Fundação Lemann em conjunto com outras instituições públicas e privadas, influenciando a política educacional brasileira, assim como ocorreu no Comonn Core americano, financiado pela Fundação Bill Gattes (CAETANO, 2019).
} 
avaliações em larga escala. Por outro lado, esvazia o conteúdo da formação dos jovens quando opta por incluir três disciplinas obrigatórias no currículo: português e matemática, o que retira dos jovens a compreensão de um mundo em constante transformação.

\section{A proposta do Empreendedorismo e a Educação}

A proposta do empreendedorismo procura se estabelecer, com as reformas, como um eixo da educação, subordinando-o à geração de alternativas para o desemprego. Os componentes centrais são o tripé capital, trabalho e Estado, em que há, nessa inter-relação, a completa sujeição do trabalho ao comando do capital e constitui a questão central da dinâmica do processo de produção e reprodução social.

Ao longo do século 20, o empreendedorismo e o empreendedor passaram a ser alvo de estudos de vários campos do conhecimento, como a Economia, Administração, Psicologia, Sociologia, cujo foco era o comportamento empreendedor dos indivíduos (Coan,2012). No Brasil, o tema surge nas universidades na década de 1980 e, especialmente, toma corpo na década de 1990 nas escolas de administração e economia, mas também no movimento empresarial com sugestões para os currículos da escola básica. Esses temas foram produzidos no contexto da reestruturação produtiva do capital e atualmente são retomadas em novas bases teóricas.

Neste contexto, a educação passa a ter nova centralidade voltada ao empreendedorismo, especialmente para os jovens, em detrimento de políticas públicas de emprego e renda. Essas propostas visavam e ainda visam solucionar, por meio de políticas e programas educacionais, problemas de ordem estrutural do capital, assim como nas reformas atuais em que o discurso da competência e do desenvolvimento das capacidades empreendedoras dos cidadãos entraram nos textos das políticas.

O empreendedorismo passou a ser incentivado também pelos organismos internacionais como solução para o desemprego, especialmente na América Latina em função dos processos de reestruturação do capitalismo, que, ao defender a reforma do Estado com base na lógica 
mercantil, utiliza-se do gerencialismo e das parcerias com o terceiro setor, redefinindo o conteúdo das políticas e o papel do setor público no atendimento das questões sociais (CAETANO, 2020).

Em 2002, a partir do Relatório Delors (1998), foi adicionando um quinto pilar: "aprender a empreender" na lógica do empreendedorismo, que legitimam o mercado como solução para os problemas sociais. A partir das instituições internacionais como a Unesco, o "aprender a empreender" passou a fazer parte da agenda educacional.

a Unesco, no encontro em Havana, Cuba, viabilizou, no Projeto Regional de Educação para a América Latina e o Caribe - PRELAC, a inclusão do quinto pilar chamado "aprender a empreender". A estes [quatro pilares], há que se reunir "Aprender a empreender", para o desenvolvimento de uma atitude proativa e inovadora, fazendo propostas e tomando iniciativas. As aprendizagens indicadas têm de capacitar cada pessoa a construir seu projeto de vida e orientar a ação das instituições educativas para que isto seja possível. (UNESCO, 2000, p. 14).

Depreende-se daí que a educação passa a ser a forma encontrada para produzir uma nova cultura, visando atender os ditames econômicos e de mercado, em que as reformas educacionais em curso têm atendido a esse propósito. Dito em outras palavras, é a educação a serviço da economia. Essas propostas culminam com as novas formas de atuação do Estado, que pretende construir uma sociedade de mercado do século 21 . Essa construção estratégica de uma sociedade de mercado busca desvincular o público do Estado recriando um espaço público "não estatal", que é um espaço e ambiente para a proliferação do empreendedorismo e seus desdobramentos. O indivíduo deixa de ser visto como cidadão, passando a ser compreendido como cliente, surgindo um novo ethos: o sujeito empresário/empreendedor (PUELLO-SOCARRÁS, 2010).

Para Puello-Socarrás (2010), o homem econômico continua reforçando o individualismo próprio do neoliberalismo, agora com nova concepção: "o homem empresário, que surge como uma exigência epistemológica, ideológica e política, que gera uma compreensão muito mais funcional e adequada para a fase do capitalismo avançado" (PUELLO-SOCARRÁS, 2010, 
p.v192), sobretudo porque torna-se uma força do mercado, conduzindo à individualidade e à meritocracia.

Essa concepção de empreendedorismo do Estado, do mundoempresa e das relações entre trabalho e capital, sintetiza o que Dardot e Laval (2016) chamam de sujeito empresarial e/ou sujeito neoliberal ou mesmo o empreendedor de si. A partir de propostas da matriz teórica do gerencialismo e da nova gestão pública (NEWMAN; CLARK, 2012), (COSTA, 2019), atuam por dentro das instituições públicas mudando a cultura do público, inclusive na educação e na escola, passando a ideia do que é eficiente e de que qualidade é a gestão privada. É no período de reestruturação do capital em que o desemprego estrutural ${ }^{4}$ e $\circ$ trabalho cada vez mais precarizado, uberizado, com a reforma da previdência, reforma trabalhista, que se insere as propostas do empreendedorismo, sobretudo, na arquitetura do Novo Ensino Médio e da BNCC no contexto de populismo autoritário e do conservadorismo que ronda a sociedade brasileira.

No Brasil, o empreendedorismo vem sendo inserido no currículo escolar a partir de propostas da classe empresarial, instituições do terceiro setor e, atualmente, a partir de políticas públicas muito bem articuladas, evidenciando as novas formas de organização do trabalho produtivo para qualificar em novas bases a juventude, com a justificativa de ser uma exigência para a educação do século 21. Ao mesmo tempo, busca influenciar o conteúdo necessário para essa formação em projetos cujo foco passa a ser especialmente a educação pública, responsável por grande parte das matrículas ${ }^{5}$ no ensino médio regular e na educação de jovens e adultos, internalizando $\circ$ ethos do trabalhador-consumidor-cidadão (Mezsàros, 2008).

\footnotetext{
4 De acordo com levantamento do IBGE (2021), o índice de desemprego no país, no primeiro trimestre de 2021, ficou da seguinte forma: desocupados 14,8 milhões; desocupação 14,7 milhões; desalentados 6,0 milhões e $29,7 \%$ a taxa de subutilização (BRASIL, 2021).

5 Em 2019 as matrículas no Ensino Médio regular somaram-se 6.842.713, conforme dados disponíveis no Laboratório de Dados Educacionais. UFPR. Disponível em: https://dadoseducacionais.c3sl.ufpr.br/\#/indicadores/matriculas. Acesso em: 16 jul. 2021.
} 
Nesse contexto de minimização dos direitos sociais, políticos e civis que essas propostas sustentam e buscam viabilizar uma educação não emancipadora para a classe trabalhadora e seus filhos. Materializando as propostas do público não-estatal e da formação de um novo ethos educacional, apresentaremos a política de empreendedorismo na educação de dois estados: Mato Grosso e Rio Grande do Sul.

\section{A Política de Empreendedorismo na Educação no MT}

São recentes tanto a Lei $N^{0} 11.233$, de 20 de outubro de 2020, que institui diretrizes para o estímulo ao empreendedorismo para alunos do ensino médio da rede de educação pública do Estado de Mato Grosso, quanto o Documento de Referência Curricular para o Ensino Médio (DRC) de Mato Grosso, analisado pelo Conselho Estadual de Educação de Mato Grosso, por meio de emissão de Parecer Pleno n 031/2020-CEE/MT, de 17 de dezembro de 2020 e publicado no Diário Oficial № 27.913 Página 33, uma adequação pelo Estado da Base Nacional Comum Curricular (BNCC). Por uma questão lógica a abordagem sobre as diretrizes e a política curricular voltadas para o empreendedorismo no Ensino Médio de MT será feita na sequência do registro sobre alguns aspectos de atividades públicas da Secretaria de Estado de Educação de Mato Grosso (SEDUC) e SEBRAE, alguns envolvendo estudantes de Ensino Médio, por acreditarmos que essas ações criaram uma ambiência cultural favorável à institucionalização de políticas voltadas para o tema do empreendedorismo na educação.

Desde 2005 a SEDUC tem realizado reuniões com O SEBRAE para discutir propostas de empreendedorismo em educação. Neste ano a reunião foi para debater o programa "Aprendendo a empreender", desenvolvido experimentalmente em três escolas da rede pública estadual de Cuiabá, Escola Estadual "Dione Augusta", "Liceu Cuiabano" e "Leônidas Antero de Matos". No site do SEBRAE a apresentação do programa é bastante suscinta. Consta de objetivo: "Conheça as principais características que um empreendedor deve ter e aprenda os conceitos básicos sobre empreendedorismo, marketing e finanças. Se você está querendo abrir um 
negócio ou se acabou de abrir este curso é para você!". A apresentação do curso é feita em um vídeo de 2 minutos e 17 segundos o qual descreve o curso, sua organização e a que e quem se destina, bem como as vantagens que apresenta ao empresário/empreendedor.

Em informações sobre o curso o site assegura que o cursista "entenderá como funcionam as definições de mercado, o marketing aplicado no cotidiano, a apuração dos resultados em um negócio e, também, quais são as características comportamentais de um empreendedor", dentre outros aspectos que indicam como obter sucesso no empreendimento. A oferta se dará em três módulos: mercado, finanças e empreendedorismo, com carga horária de 16 horas, no formato online e 30 dias de duração. É destinado a MEl (Microempreendedor individual), futuro empresário.

Outros encontros foram promovidos entre SEDUC e SEBRAE ao longo de 2017 a outubro de 2020. Em 2017 o Secretário de Educação, Esporte e Lazer de Mato Grosso se reuniu com representantes do SEBRAE, da Secretaria de Estado de Cultura e da Secretaria de Estado de Desenvolvimento Econômico para debater sobre a ampliação de projetos de empreendedorismo para os alunos e professores da rede estadual. "A Seduc, por meio do Mato Grosso Criativo, programa intersetorial que articula ações de cinco secretarias de Estado, já realiza trabalhos voltados para o empreendedorismo - e a expectativa é que o programa possa incluir alunos e até mesmo professores com palestras e capacitações". Iniciativas como estas foram reverberando nas escolas e, em 2020, foram desenvolvidos projetos em escolas da rede pública estadual, como o projeto intitulado Sustentabilidade e Empreendedorismo, em escola estadual de Várzea Grande - MT e palestra on-line desenvolvida em parceria entre SEDUC e SEBRAE intitulada "A Mágica do empreendedorismo" destinada a estudantes de 83 escolas de ensino médio do estado. Considerada atividade pedagógica diferenciada para alunos de ensino médio, o objetivo da palestra foi "desmistificar o tema e a educação financeira com os estudantes". 
Como parte desse movimento o empreendedorismo ocupou lugar de destaque no Documento de Referencia Curricular de Mato Grosso (DRC-MT) para o Ensino Médio, uma regulamentação da Base Nacional Comum Curricular para o Ensino Médio, sobretudo nas Eletivas e Trilhas de Aprofundamento. A DRC foi elaborada com participação dos sujeitos escolares via consulta pública e algumas audiências públicas realizadas no espaço escolar; contou com assessoria e "leitura crítica" do Movimento pela Base e de consultores externos, indicados pelo Instituto Reúna, organização social, constituída por ex-secretários de educação. O empreendedorismo é apresentado na DRC tanto na Formação Técnica e Profissional quanto nos Itinerários Formativos formados por Componentes Curriculares Eletivas, Projeto de Vida e Trilhas de Aprofundamento. Na DRC os Itinerários Formativos:

[...] são compreendidos como o conjunto de unidades curriculares que ampliam a possibilidade do protagonismo juvenil no Ensino Médio, pois o estudante poderá ter opções de escolha para aprofundar seus conhecimentos e se preparar para o mundo do trabalho, de forma a contribuir para a construção de soluções de problemas específicos da sociedade. (MATO GROSSO, 2020, p. 406).

Dentre os quatro eixos estruturantes dos Itinerários Formativos, encontra-se o Empreendedorismo. A ênfase desse eixo é "expandir a capacidade dos estudantes de mobilizar conhecimentos de diferentes áreas para empreender projetos pessoais ou produtivos articulados ao seu projeto de vida" (BRASIL, 2018). A DRC assinala que as Competências Gerais seis (06) e dez (10) se articulam ao Empreendedorismo. Nesta última Competência espera-se que o estudante "deve ser capaz de agir pessoal e coletivamente com autonomia, responsabilidade, flexibilidade, resiliência e determinação para tomar decisões com base em princípios éticos, democráticos, inclusivos, sustentáveis e solidários (MATO GROSSO, 2020, p. 411).

A concepção de sociedade na qual o empreendedorismo encontra lugar e descrita no DRC é marcada "pela incerteza, volatilidade e mudança permanente". Aponta que o estudante deve "se adaptar a diferentes contextos para que seja capaz de criar novas oportunidades para si e para 
os demais". Assim, o documento (MATO GROSSO, 2020) apresenta "uma possibilidade de sequência e/ou atividades educativas a serem desenvolvidas para o trabalho pedagógico com unidades curriculares desse eixo estruturante":

1. Identificação de potenciais, desafios, interesses e aspirações pessoais;

2. Análise do contexto externo, inclusive em relação ao mundo do trabalho;

3. Elaboração de um projeto pessoal ou produtivo;

4. Realização de ações-piloto para testagem e aprimoramento do projeto elaborado;

5. Desenvolvimento ou aprimoramento do projeto de vida dos estudantes. (MATO GROSSO, 2020, p. 411);

Como o eixo Empreendedorismo deve estar articulado ao projeto de vida significa que será ofertado como componente curricular nos três anos do ensino médio, como bloco comum a todos os estudantes. No DRC o projeto de vida tem por objetivo principal:

[...] desenvolver a capacidade do estudante de significar a sua existência, permitindo que tomadas de decisões façam sentido e sejam imbuídas de planejamento. Assim, o estudante compreenderá que a forma como conduzirá sua vida é passível de escolhas, necessitando da capacidade de planejar o futuro e agir no presente com autonomia e responsabilidade. (MATO GROSSO, 2020, p. 407).

O empreendedorismo, termo fortemente emprestado do meio empresarial, ganha centralidade no DRC e encontrou abrigo na Lei $N^{\circ}$ 11.233, de 20 de outubro de 2020, que institui diretriz para o estímulo ao empreendedorismo para alunos do ensino médio da rede de educação pública do Estado de Mato Grosso, tramitou na Assembleia Legislativa de Mato Grosso, de 04 de setembro de 2019, até ser aprovada em segunda votação de 04 de outubro de 2020 e sancionada pelo governador do estado em 19 de outubro de 2020. O Parágrafo Único do Artigo $1^{\circ}$ da referida Lei define empreendedorismo como: "o aprendizado pessoal que, impulsionado pela motivação, criatividade e iniciativa, capacita para a descoberta vocacional, a percepção de oportunidades e a construção de um projeto de vida". Como já mencionado, a DRC traz o projeto de vida 
como parte da carga horária do ensino médio, em sua organização, tendo nas Eletivas e Trilhas de Aprofundamento a base de tal proposta. Tanto a Lei $n^{\circ} 11.233$ quanto a DRC estão em consonância com o projeto piloto em andamento em 12 escolas de ensino médio do Sistema estadual de Ensino de Mato Grosso, que implementa a organização curricular induzida pelo Ministério da Educação (MEC), voltados para o "novo" ensino médio de tempo integral e cujo projeto de vida é um de seus componentes curriculares.

O Artigo $2^{\circ}$ da referida Lei aponta as diretrizes que orientarão a promoção do empreendedorismo para alunos do ensino médio da rede pública:

I - a busca pela elevação da escolaridade com aulas teóricas e práticas sobre empreendedorismo;

II - a promoção do acesso ao conhecimento do empreendedorismo de forma unificada;

III - o acesso aos ensinamentos preferencialmente no contraturno escolar;

IV - o esforço pela preparação dos grupos na real transformação para futura inserção no mercado de trabalho, renda e desenvolvimento profissional;

$\checkmark$ - a busca pela implementação de acordos de cooperação na ministração das aulas com a participação efetiva e monitoramento por alunos de graduação e pós-graduação de universidades e faculdades públicas e particulares, entidades com e sem fins lucrativos e demais pessoas físicas e jurídicas com notável conhecimento na área do empreendedorismo;

VI - a priorização da supervisão por docentes efetivos de instituições de ensino superior públicas e privadas;

VII - o encorajamento na concepção de planos produtivos sustentáveis;

VIII - o estímulo à subvenção a empresa que empregar alunos participantes;

IX - a busca por instrumentos e ferramentas que convirjam para a integração social, o incremento da produtividade e de políticas sustentáveis;

$X$ - a preferência pelos seguintes temas do empreendedorismo, com a contemplação dos seguintes preceitos e metodologias:

a) noções de empreendedorismo, intraempreendedorismo e inovação; 
b) identificação de oportunidades, preparação para o mercado de trabalho e primeiro emprego;

c) construção de competências profissionais, habilidades sociais e marketing pessoal e tecnologias em redes sociais;

d) motivação para superação de obstáculos e estímulo à criatividade, formando alunos autônomos, éticos e responsáveis;

e) construção de conhecimentos em economia e finança familiar;

f) orientação vocacional e planejamento de carreira;

g) educação financeira, cultura organizacional e gestão de negócios e de mercado;

h) ampliação da relação aluno/escola e comunidade;

i) vivências, dinâmicas de grupo, autoconhecimento e estímulo a debates;

j) atividades lúdicas;

k) oficinas e estudos de caso.

O discurso do empreendedorismo é funcional a uma racionalidade neoliberal baseada no individualismo. Ganha força na conjuntura nacional e pode ser melhor compreendido no contexto de desconstrução de direitos, sobretudo a partir de 2016, como as alterações na legislação trabalhista no Brasil, instrumentalizada pela Lei $n^{\circ}$ 13.467, de 2017; sob a justificativa de combater o desemprego e a crise econômica, a Lei n 13.429, de 31 de março de 2017, que permite a terceirização ilimitada, irrestrita, sem qualquer regulamentação, em todas as atividades da empresa. Estes são alguns exemplos emblemáticos das profundas alterações no mundo do trabalho, conforme apontam estudos de Antunes (2020), acerca da precarização do trabalho, do trabalho intermitente e uberização e o trabalho digital no limiar da indústria 4.0.

\section{A Politica de Empreendedorismo na Educação no RS}

No Rio Grande do Sul, o incentivo ao setor privado e empresarial está em crescimento, incluindo investimentos por parte do Estado e fortemente caracterizados pelo discurso da inovação, tecnologia, modernização, empreendedorismo em detrimento da formação humana integral e omnilateral. Os objetivos, como justiça social, vêm sendo gradualmente 
convertidos em objetivos de eficiência e racionalidade de mercado. Essa racionalidade integra a política de empreendedorismo para a educação (CAETANO, 2020).

A política do empreendedorismo no estado não é nova. Em 2006 foi instituída a Política Estadual de Empreendedorismo a ser desenvolvida nas escolas de nível médio e escolas técnicas do RS. A Lei n 12.616, de 8 de novembro de 2006, foi atualizada pelo governador Eduardo Leite através da Lei $n^{\circ} 15.410$, de 19 de dezembro de 2019. A Lei "Institui a Política Estadual de Educação Empreendedora, a ser desenvolvida no âmbito das escolas técnicas e das escolas de nível médio do Estado do Rio Grande do Sul". A lei apresenta ainda os conceitos de empreendedorismo, cultura empreendedora e prática empreendedora:

Art. $1^{\circ}$ Fica instituída a Política Estadual de Educação Empreendedora, a ser desenvolvida no âmbito das escolas técnicas e das escolas de nível médio do Estado do Rio Grande do Sul. $\S 1^{\circ}$ Entende-se por empreendedorismo o aprendizado pessoal que, impulsionado pela motivação, criatividade e iniciativa, capacita para a descoberta vocacional, a percepção de oportunidade e a construção de um projeto de vida.

$\S 2^{\circ}$ Entende-se por cultura empreendedora nas instituições de ensino a internalização de comportamento e atitude empreendedores de alunos e professores para que se tornem responsáveis pelo seu próprio futuro e das comunidades em que vivem.

$\S 3^{\circ}$ Entende-se por prática empreendedora iniciativas ou experiências educacionais que acontecem dentro e fora da sala de aula e que têm como objetivos inspirar e proporcionar oportunidades para os estudantes se envolverem com o empreendedorismo, como disciplinas, técnicas de ensino, materiais didáticos, pesquisas, projetos interdisciplinares, eventos culturais, feiras, programas de tutoria e mentoria;

III - no art. $2^{\circ}$, fica acrescido o inciso $\mathrm{V}$, conforme segue:

Art. $2^{\circ}[\ldots]$

$\checkmark$ - desenvolver as competências empreendedoras nos alunos.;

Art. $3^{\circ}$ A implementação e a execução da Política Estadual de Educação Empreendedora terão como diretrizes: ...

III - estimular a implantação de práticas educacionais que congreguem a comunidade escolar e a inovação nas práticas educacionais e nos projetos que explorem ideias de negócios; ... VII ampliar, promover e disseminar a educação empreendedora nas instituições de ensino por meio da oferta de conteúdos de empreendedorismo nos currículos, objetivando a consolidação da cultura empreendedora na educação; VIII - desenvolver características comportamentais empreendedoras, como autonomia e protagonismo. (RIO GRANDE DO SUL, 2019, p. 1). 
A legislação (RIO GRANDE DO SUL, 2019, p. 2) diz que a Secretaria da Educação e a Secretaria de Inovação, Ciência e Tecnologia poderá detalhar os conteúdos relativos à Política Estadual Empreendedora, prevendo a inclusão de conteúdos e atividades que promovam a cultura empreendedora nos projetos pedagógicos e planos escolares, para a realização de práticas empreendedoras no processo de ensino e aprendizagem. Tudo isso com ações de caráter curricular ou extracurricular voltadas aos estudantes de escolas técnicas e de escolas de nível médio do RS.

Caetano (2020) já apresentava que a opção da SEDUC como órgão público, que deveria defender os interesses da comunidade escolar, tem atuado alinhada a instituições do terceiro setor como a Fundação Lemann, Fundação Itaú Social e o Instituto Unibanco e repassando as decisões sobre a educação para essas entidades. Por exemplo o Projeto Educação Gaúcha Conectada é uma parceria entre SEDUC-RS e BNDES cujo orçamento do projeto é de 3,1 milhões. As instituições envolvidas são Fundação Lemann, Fundação Itaú Social e CIEB - Centro de Inovação para a Educação Brasileirab. A execução do projeto e seu conteúdo nas escolas públicas estaduais passa a ser das instituições não públicas, mas com financiamento público, característica do Estado Empreendedor.

\section{A atuação do SEBRAE e a educação para a Cultura Empreendedora no RS}

O Serviço Brasileiro de Apoio às Micro e Pequenas Empresas (SEBRAE) é uma entidade privada que promove a competitividade e $O$ desenvolvimento sustentável dos empreendimentos de micro e pequeno porte. Conforme informações do site?, há mais de 40 anos atua com foco no fortalecimento do empreendedorismo e na aceleração do processo de formalização da economia por meio de parcerias com os setores público e

6 Dados obtidos em: <http://difusora890.com.br/insercao-de-tecnologia-para-usopedagogico-beneficiara-28-mil-alunos-no-rs/>._Acesso em: 2 nov. 2020.

${ }^{7}$ Disponível em:

shttps://www.sebrae.com.br/sites/PortalSebrae/educacaoempreendedora>. Acesso em: 10 nov. 2020. 
privado, programas de capacitação, acesso ao crédito e à inovação, estímulo ao associativismo, feiras e rodadas de negócios.

O Sebrae atua em todo o território nacional oferecendo cursos, seminários, consultorias e assistência técnica para pequenos negócios de todos os setores. Também apresenta como um dos objetivos promover a educação e a cultura empreendedora, cuja descrição é desenvolver uma cultura voltada para o empreendedorismo, focado no público jovem e na educação (https://sebraers.com.br/atuacao/2020). No RS, o Sebrae-RS está ligado às entidades da classe empresarial. Além disso, atua fortemente na disseminação de uma cultura empreendedora na educação, pois acredita que, formando jovens com perfil mais protagonista, teremos empreendedores mais preparados para os novos desafios da sociedade.

O Sebrae tem apresentado várias propostas para a educação gaúcha através de eventos com foco na educação empreendedora, especialmente para professores e profissionais envolvidos com educação formal. Em relação aos estudantes, atua em parceria com outros sujeitos coletivos, como ONGS, e contratação de serviços para consultoria e palestras. Nesse programa para estudantes:

A ideia é despertar os sonhos e abrir perspectivas para jovens estudantes de escolas públicas em situação de vulnerabilidade social. Essas iniciativas reforçam a implementação e a execução da Política Estadual de Educação Empreendedora que busca estimular a implantação de práticas educacionais que congreguem a comunidade escolar e a inovação nas práticas educacionais e nos projetos que explorem ideias de negócios. Visa também ampliar, promover e disseminar a educação empreendedora nas instituições de ensino por meio da oferta de conteúdos de empreendedorismo nos currículos. O propósito é a consolidação da cultura empreendedora na educação e o desenvolvimento de características comportamentais empreendedoras, como autonomia e protagonismo. (SEBRAE, 2020, s/p).

O estado do RS criou o Programa Jovem RS Conectado no Futuro. Esse Programa gera selos de inovação e salas para estimular o empreendedorismo em escolas estaduais em parceria com universidades e instituições privadas cujo objetivo é estimular a criação de novos projetos nas escolas, o empreendedorismo e a criatividade nas instituições. 
O Projeto Escola Empreendedora integra O Programa Jovem Conectado - RS. Na apresentação para a imprensa, foi assim descrito:

É a escola em que os componentes curriculares se articulam nas diferentes etapas de ensino, com o propósito de estimular os estudantes a desenvolver habilidades e competências que fomentem o seu protagonismo. Enfatiza a aprendizagem criativa e colaborativa, e o "fazer mão na massa", voltados para a inserção no mundo do trabalho e na cocriação de soluções aos seus desafios e de sua comunidade. Apresenta como principal parceiro o SEBRAE e visa atingir 300 escolas que implantaram o Novo Ensino Médio, dez por CRE. (SEBRAE, 2019, online).

O projeto Escola Empreendedora apresenta os seguintes indicadores: Sustentabilidade Econômica, Protagonismo e Cooperação; Criação de Produtos e Serviços; Fomento de Parcerias; Educação Financeira (SEDUC, Programa Jovem RS, 2019).

Recebe o selo de Escola Empreendedora, aquela escola que atende os indicadores propostos pelo programa. Em outras palavras, aquela que for merecedora e que, segundo os indicadores, devem desenvolver projetos que gerem ganhos, que contemplem características do sujeito empreendedor ou socioemocionais, que resolvam problemas e que façam parcerias público-privadas. Quem assume o protagonismo sobre o conteúdo educacional neste programa é o Sebrae.

Em uma perspectiva comparada de como a educação empreendedora tem sido implantada nos estados do MT e RS, apresentamos o quadro abaixo que mostra que tanto no Mato Grosso quanto no Rio Grande do Sul o tema é introduzido via legislação, de modo a assegurar sua implementação.

Quadro 1 - Educação Empreendedora no Mato Grosso e no Rio Grande do Sul

\begin{tabular}{|c|c|c|}
\hline EIXOS & MATO GROSSO & RIO GRANDE DO SUL \\
\hline NORMATIVA & $\begin{array}{l}\text { Lei } n^{\circ} 11.233 \text {, de } 20 \text { de outubro } \\
\text { de } 2020 \text {, que institui diretriz para } \\
\text { orámulo ao } \\
\text { empreendedorismo para alunos } \\
\text { do ensino médio da rede de }\end{array}$ & $\begin{array}{l}\text { Lei } n^{\circ} 15.410 \text {, de } 19 \text { de dezembro } \\
\text { de 2019. A lei Institui a Politica } \\
\text { Estadual de Educação } \\
\text { Empreendedora, a a ser } \\
\text { desenvolvida no âmbito das }\end{array}$ \\
\hline
\end{tabular}




\begin{tabular}{|c|c|c|}
\hline & $\begin{array}{l}\text { educação pública do Estado } \\
\text { de Mato Grosso. }\end{array}$ & $\begin{array}{l}\text { escolas técnicas e das escolas de } \\
\text { nível médio. }\end{array}$ \\
\hline CONCEITO & $\begin{array}{l}\text { o aprendizado pessoal que, } \\
\text { impulsionado pela motivação, } \\
\text { criatividade e iniciativa } \\
\text { capacita para a descoberta } \\
\text { vocacional, a percepção de } \\
\text { oportunidades e a construção } \\
\text { de um projeto de vida. }\end{array}$ & $\begin{array}{l}\text { o aprendizado pessoal que, } \\
\text { impulsionado pela motivação, } \\
\text { criatividade e iniciativa capacita } \\
\text { para a descoberta vocacional, a } \\
\text { percepção de oportunidades e a } \\
\text { construção de um projeto de vida. }\end{array}$ \\
\hline CURRICULO & $\begin{array}{l}\text { Projeto de vida como parte da } \\
\text { carga horária do ensino médio, } \\
\text { em sua organização, tendo nas } \\
\text { Eletivas e Trilhas de } \\
\text { Aprofundamento a base de tal } \\
\text { proposta. }\end{array}$ & $\begin{array}{l}\text { Projeto de vida e trilhas como } \\
\text { parte da carga horária do ensino } \\
\text { médio (ainda não aprovado). }\end{array}$ \\
\hline PARCEIRO & Parceiro na execução: SEBRAE & Parceiro na execução: SEBRAE \\
\hline $\begin{array}{l}\text { DOCUMENTO } \\
\text { CURRICULAR }\end{array}$ & $\begin{array}{l}\text { Empreendedorismo } \\
\text { destaque no Documento de } \\
\text { Referência Curricular de Mato } \\
\text { Grosso (DRC-MT) para o Ensino } \\
\text { Médio, Formação Técnica e } \\
\text { Profissional e Itinerários } \\
\text { Formativos }\end{array}$ & $\begin{array}{l}\text { Na proposta de Documento de } \\
\text { Referência Curricular do RS para o } \\
\text { Ensino Médio, o foco é a } \\
\text { Formação Técnica e Profissional e } \\
\text { nos Itinerários Formativos em geral. }\end{array}$ \\
\hline ASSESSORIA & $\begin{array}{l}\text { Assessoria e "leitura crítica" do } \\
\text { Movimento pela Base (MPB) e } \\
\text { de consultores externos, } \\
\text { indicados pelo Instituto Reúna }\end{array}$ & $\begin{array}{l}\text { Consultores externos ligados a } \\
\text { institutos e fundações ligados ao } \\
\text { MPB }\end{array}$ \\
\hline
\end{tabular}

Fonte: organizado pelas autoras (2021).

Destacamos no Quadro 1 que, embora estados com características distintas, as formas nas quais o 'Novo Ensino Médio' vem sendo implantado são muito semelhantes, incluindo parceiro comum: o Sebrae que tem atuado junto às secretarias estaduais na construção e execução do currículo do EM, produzindo conteúdo curricular e atuando na formação de professores e alunos.

Os programas oferecidos pelo Sebrae para a educação pública visam influenciar os conteúdos dos programas ofertados nas escolas públicas estaduais. Além disso, a educação para o empreendedorismo, como política, esvazia o conteúdo educacional. Por outro lado, ao conceber a capacidade empreendedora como inata, cabe à escola simplesmente despertá-la e desenvolvê-la, secundarizando os conhecimentos sociais, históricos e filosóficos socialmente construídos em detrimento de uma educação voltada à técnica e ao saber fazer. 
A Resolução CNE/CEB 3/2018 apresenta o empreendedorismo como um dos quatro eixos dos itinerários formativos, a temática já vinha sendo introduzida em uma ambiência influenciada pelas instituições privadas que atuaram fortemente na BNCC e EM, nas reformas trabalhistas e da previdência num contexto de minimização dos direitos sociais, políticos e civis.

Percebemos que as políticas de empreendedorismo vêm sendo implantadas de fora para dentro da escola e pensadas por sujeitos que não são da área educacional. Os professores passam a meros executores da proposta, visto que foi construída pela base empresarial e articulada junto ao poder público por entidades, como o SEBRAE que visam promover uma mudança de cultura justamente no que é público. Buscam criar um novo ethos na educação brasileira sob a lógica da reestruturação produtiva e do gerencialismo, subordinando a educação aos ditames econômicos e do mercado, propondo um novo projeto educacional. Nós defendemos a formação omnilateral para a emancipação humana que se afasta da proposta de empreendedorismo apresentada pelo Sebrae.

\section{CONSIDERAÇÕES}

A educação enquanto bem público deve ter o Estado como garantidor do direito à educação e o que vem ocorrendo é a privatização por dentro da escola a partir do conceito de público não estatal. A escola permanece pública, mas o conteúdo da gestão, das formações de gestores e professores, e do processo de ensino e aprendizagem passam a ser geridos por grupos privados, alheios à escola.

O Ensino médio que visa a formação dos jovens brasileiros passa a ter uma formação sem memória histórico-cultural da sociedade brasileira e mundial, implicando na impossibilidade de compreender o mundo atual, com esvaziamento dos conteúdos fundamentais de todas as áreas do conhecimento e abdica, por opção política, da formação integral e integrada dos jovens. 
Ao delegar a educação para terceiros ou introduzir as parcerias público-privadas, os governos federal e estadual transformam a educação em um serviço a ser comercializado em um grande mercado. Ao mesmo tempo esvaziam a gestão democrática, a autonomia da escola, a participação em instâncias decisórias e colegiadas, o diálogo com a comunidade escolar e atingem o direito à educação básica, uma conquista recente da sociedade brasileira. Essa natureza antidemocrática é explicada por Dardot e Laval $(2019, \mathrm{~s} / \mathrm{p})$, como "processo de desdemocratização da educação e da sociedade, pelo qual a democracia se esvazia de sua substância, sem que se suprima formalmente".

Sob o slogan de formar empreendedores, entendemos como uma forma de socializar a nova geração de estudantes e de professores em uma nova ordem de trabalho, desfocando dos direitos e estabilidade no emprego, reduzindo custos dos empresários e favorecendo o grande capital.O empreendedorismo cria uma falsa ilusão ao imaginar poder eliminar o desemprego em um Estado incapaz de preservar trabalho e direitos à sua população.

Nesse quadro de desemprego estrutural, os jovens são levados a incorporar a ideia de ser um empresário da sua própria formação como exigência da empregabilidade.

O novo ethos educacional para o século 21 tem como protagonismo a educação para o empreendedorismo, a inovação e a tecnologia que cumpre o papel destinado à formação da juventude de influenciar seus modos de pensar, agir e sentir, para que o jovem atue como protagonista na produção e reprodução de valores do mercado para a construção dessa nova sociedade.

\section{REFERÊNCIAS}

ABDALA, P. R. Z.; PUELLO-SOCARRÁS; J. F. Reflexiones sobre la Administración pública y el Neoliberalismo en Nuestramérica, Siglo XXI. Revista Eletrônica da Administração, v. 25, n. 2, p. 22-39, 2019.

ANTUNES.Ricardo(org). Uberização, trabalho digital e indústria 4.0.1 ${ }^{a}$ edição. São Paulo:Boitempo, 2020. 
BRASIL. Instituto Brasileiro de Geografia e Estatística. Desemprego. IBGE. [on line]. Disponível em: <https://www.ibge.gov.br/explica/desemprego.php>. Acesso em; 15 jul. 2021.

BRASIL.Ministério da Educação.Conselho Nacional de Educação.Câmara de Educação Básica. Resolução CNE/CEB n ${ }^{3}$, de 21 de novembro de 2018.Atualiza as Diretrizes Curriculares Nacionais para o Ensino Médio.Brasília: DOU, 22.11.2018.

BRASIL. Presidência da República. Secretaria Geral. Subchefia para Assuntos Jurídicos. Lei $\mathbf{n}^{\circ}$ 13.415, de 16 de fevereiro de 2017. Altera as Leis $n_{-}^{\circ} 9.394$, de 20 de dezembro de 1996, que estabelece as diretrizes e bases da educação nacional. Brasília: DOU, 17.2.2017.

BRASIL. Presidência da República. Secretaria Geral. Subchefia para Assuntos Jurídicos. Lei $\mathbf{n}^{\circ} \mathbf{1 3 . 2 7 8}$, de 2 de maio de 2016.

Altera o $\S 6^{\circ}$ do art. 26 da Lei $n^{\circ} 9.394$, de 20 de dezembro de 1996, que fixa as diretrizes e bases da educação nacional, referente ao ensino da arte.

Brasília: DOU, 3.5.2016

CAETANO.M.R. Ensino Médio e Empreendedorismo na Rede Estadual do Rio Grande do Sul. In: BAIRROS.M; MARCHAND.P.(Orgs.) Ensino Médio: desafios e contradições. 1.edição. Porto Alegre: Cirkula: 2020.

CAETANO.M.R. Os sujeitos e a proposta educacional da Base Nacional Comum Curricular: entre o público e o privado. Revista Teoria e Prática da Educação, UEM, Maringá -PR, v.15, n.1, p.118-136, 2019.

CIAVATTA, M. Formação integrada caminhos para a construção de uma escola para os que vivem do trabalho. In: SEED. O Ensino Médio integrado à educação profissional: concepções e construções a partir da implantação na Rede Pública Estadual do Paraná. Curitiba: SEED-PR, 2008.

COAN. M. Educação para o empreendedorismo como estratégia para formar um trabalhador de novo tipo. IX Anped Sul. Caxias do Sul, 2012. Disponível em http://www.ucs.br/etc/conferencias/index.php/anpedsul/9anpedsul/paper/ viewFile/2780/214. Acesso em jun. 2021.

COSTA, M. de O. Contrarreformas, Nova Gestão Pública e relações público-privadas: mapeando conceitos, tendências e influências na educação. RBPAE - Revista Brasileira de Política e Administração da Educação, ANPAE, Brasília-DF, v. 35, n. 1, p. 159 - 179, jan./abr. 2019.

DARDOT, P.; LAVAL, C. A nova Razão do mundo: ensaio sobre a sociedade neoliberal. São Paulo: Boitempo, 2016. 
DARDOT, P.; LAVAL, C. Anatomia do novo neoliberalismo. Artigo de Pierre

Dardot e Christian Laval. IHU on line. São Leopoldo: Unisinos, 25 julho de 2019.

DELORS, J. EDUCAÇÃO, UM TESOURO A DESCOBRIR. Relatório para a UNESCO da Comissão Internacional sobre Educação para o século XXI. São Paulo: CORTEZ EDITORA; Brasília: UNESCO, 1998

FRIGOTTO, G.; CIAVATTA, M.; RAMOS, M. (Orgs.). Ensino Médio Integrado: concepção e contradições. 3. ed. São Paulo: Cortez, 2012.

KRÜGER, R. S. Ensino médio integrado: desafios e possibilidades para o avanço na perspectiva da concepção de integração. Dissertação (Mestrado) - Instituto Federal de Educação, Ciência e Tecnologia Sul-riograndense, Programa de Mestrado Profissional em Educação Profissional e Tecnológica em Rede Nacional, Charqueadas - RS, 2019.

KUENZER, A. Z. Da dualidade assumida à dualidade negada: o discurso da flexibilização justifica a inclusão excludente. Educação \& Sociedade, Campinas, v. 28, n. 100, p. 1153-1178, out. 2007.

MANCUSO, J. H. SEBRAE 30. Parceiro dos brasileiros. Brasília: SEBRAE Nacional, 2002

MATO GROSSO. Assembleia Legislativa do Estado de Mato Grosso. Secretaria de Serviços Legislativos. Lei $\mathbf{n}^{\circ}$ 11.233, de 20 de outubro de 2020. Institui diretriz para o estímulo ao empreendedorismo para alunos do ensino médio da rede de educação pública do Estado de Mato Grosso. Cuiabá - MT: DOE, 20.10.2020.

MATO GROSSO. Governo do Estado. Secretaria de Estado de Educação. Conselho Estadual de Educação. Parecer Pleno n 031/2020-CEE/MT, de 17 de dezembro de 2020. Documento de Referência Curricular para Mato Grosso - Etapa Ensino Médio. Cuiabá - MT: DOE, 12.01.2021

MÉSZÁROS, I. A educação para além do capital. São Paulo: Boitempo Editorial, 2008.

NEWMAN, J.; CLARKE, J. Gerencialismo.Educação e Realidade, UFRGS, Porto Alegre -RS, v.37, n.2,2012

PUELLO-SOCARRÁS, J. F. Del homo oeconomicus al homo redemptoris: Emprendimiento y Nuevo Neo-liberalismo. Otra Economía - Volumen IV - No 6. 2010. Disponível em: <www.riless.org/otraeconomia>. Acesso em: maio 2020.

PUELLO-SOCARRÁS, José Francisco. Un nuevo neo-liberalismo. Emprendimiento y nueva administración de "lo público". Revista 
Administración \& Desarrollo, No. 49, Bogotá, D. C., Primer semestre - Junio de 2008.

RAMOS, M. Ensino Médio Integrado: da conceitualização à operacionalização. In: Cadernos de Pesquisa em Educação - PPGE/UFES.

Vitória - ES, v. 19, n. 39, p.15-29, jan./jun. 2014.

RAMOS, M. Concepção de Ensino Médio Integrado. Seminário sobre ensino médio, realizado pela Superintendência de Ensino Médio da Secretaria de Educação do Estado do Rio Grande do Norte -Natal, 2007.

RIO GRANDE DO SUL. Governo do Estado. Lei $\mathbf{n}^{\circ}$ 15.410, de 19 de dezembro de 2019. Altera a Lei $n^{\circ} 12.616$, de 8 de novembro de 2006 e Institui a Política Estadual de Educação Empreendedora, a ser desenvolvida no âmbito das escolas técnicas e das escolas de nível médio do Estado do Rio Grande do Sul. Porto Alegre - RS: Palácio Piratini, 19.12.2019.

RIO GRANDE DO SUL. Secretaria da Educação. Jovem RS - Conectado no Futuro. Porto Alegre - RS: SEDUC, 3.9.2019.

SEBRAE-RS. Sebrae RS é parceiro do Programa Jovem RS Conectado ao

Futuro. Organização irá atuar na elaboração das competências para identificar as escolas empreendedoras.26/9/2019. Disponível em:

<https://sebraers.com.br/sebrae-rs-e-parceiro-do-programa-jovem-rsconectado-ao-futuro/ $\geq$. Acesso em: 5 jul. 2021.

UNESCO. O Marco de Ação de Dakar Educação Para Todos: atendendo nossos compromissos coletivos. Dakar, Senegal: Cúpula Mundial de Educação, 2000.

Recebido em: 03 de agosto de 2021.

Aprovado em: 30 de agosto de 2021.

Publicado em: 24 de setembro de 2021.

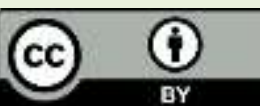

